\title{
Organization of Propaganda Forums (Such as COP21) by Some Heads of State Seriously Disturbs Scientific Debates on Real Causes of Climate Global Changes
}

\author{
César Mbane Biouele \\ Laboratory of Earth's Atmosphere Physics, Department of Physics, University of Yaoundé I, Yaoundé, Cameroun \\ Email: cesar.mbane@yahoo.fr
}

Received 27 December 2015; accepted 24 January 2016; published 27 January 2016

Copyright @ 2016 by author and Scientific Research Publishing Inc.

This work is licensed under the Creative Commons Attribution International License (CC BY).

http://creativecommons.org/licenses/by/4.0/

(c) (i) Open Access

\begin{abstract}
Faced with many problems (practically insoluble) that call them politicians lie (to save their careers), claiming that they are resolutely interested to earth's environment protection. Unnecessary (for some) and outrageously expensive (for others) organization of COP21 is part of this logic of distracting the "international community" by (for example) making believe that the reduction of $\mathrm{CO}_{2}$ emissions is something reachable for humans and that this reduction can weaken the harmful effects of global warming such as: floods, endless droughts, melting glaciers, upsurge of hurricanes or tornadoes, etc. Can the "binding" commitments taken during COP21 be effective? Our objective and immediate answer is: No. Because those who have made commitments, ignore completely how the $\mathrm{CO}_{2}$ (main object of their attentions) or sulfur dioxide $\left(\mathrm{SO}_{2}\right)$ behave with respect to some predominant elements of the atmosphere such as clouds. Moreover, a significant number of the propaganda forums' stakeholders ignores that earth's atmosphere is considerably affected by the radiation from the sun and that the intensity of solar radiation received at the surface of the earth mainly depends on the Earth-Sun distance and the precession angle of the earth relative to its orbit. Earth-Sun distance and precession angle of the Earth's orbit vary in space and time: this Physical law must be constantly present in our minds. Teaching the fundamentals of Atmospheric Physics allows solar radiation and its derivative forms (e.g.: winds, snow or rains) to cease to be a mystery in the mind of the international community.
\end{abstract}

\section{Keywords}

Earth's Environment Protection, Propaganda Forums, Earth-Sun Distance, Precession Angle of the Earth, $\mathrm{CO}_{2}$ or Sulfur Dioxide $\left(\mathrm{SO}_{2}\right)$ Behave with Respect to Clouds 


\section{Introduction}

Organization of propaganda forums (such as COP21) by some heads of state seriously disturbs scientific debates on real causes of climate global changes. Indeed, rather than engage the "international community" in military conflicts that no one can decide the end, Presidents at the head of the militarily and economically powerful countries would benefit from investing helpful (e.g., by boosting the disclosure of knowledge on the Earth's Atmosphere Physics through international forums as well as organized and publicized that COP21). This will at least better reframe the debate on Climate Changes and the protection of our environment which in this day is severely exposed to abject forms of pollution. Paying a little more attention to what is happening around us allows to realize that pollution is growing exponentially in many places of our planet (e.g.: oceans' floor pollution, wetlands' pollution, unbridled pollution of the atmosphere, forests' pollution during the extraction of certain minerals, etc.). These alarming signs announce so deep changes or complete destruction of beings (animals, plants and humans) that live on the earth.

\section{Importance of the Sun Particularly in Its Relationship to the Earth}

Because of the importance of the sun, everyone should be familiar with it, particularly in its relationship to the earth. For purposes of this paper, only a few outstanding facts will be considered. Elementary textbooks of astronomy or dynamic balance meteorology book like mine [1] usually contain a fairly complete chapter on the sun, and the reader of this paper is referred to them. Among other things, these paper relates that the sun (at least the outer portion of it) is a mass of flaming gas (Figure 1) having a temperature of about $6000 \mathrm{~K}$ or about $10,300^{\circ} \mathrm{F}$. Most of its heat is wasted, as far we are concerned; by passing out into endless space, only an infinitesimally small portion of the whole output being intercepted by the earth and other planets. Yet to us this relatively small amount of heat which we receive (Figure 2) from the sun represents a huge store of energy.

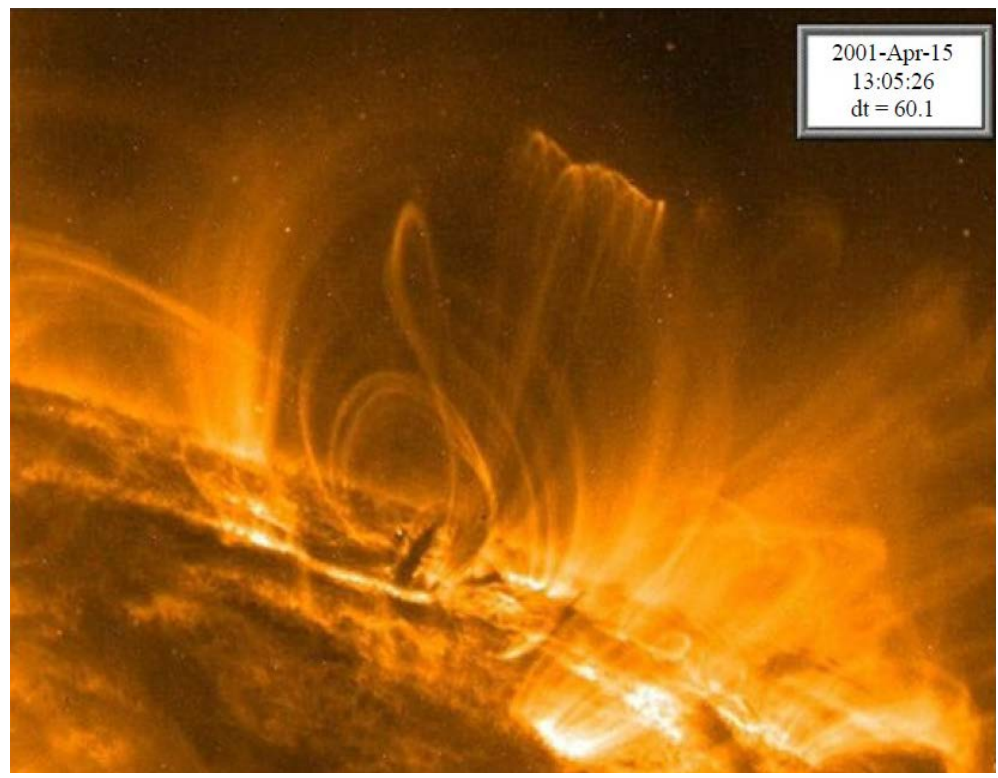

Figure 1. Solar identity card. Age: 4.5 billion years; Radius: 696,000 km (110* Earth radius); Weight: $1.991030 \mathrm{~kg}$ (333,000 * Earth mass); Chemical composition (by number of atoms): Hydrogen: $94 \%$, Helium: 6\%, and traces mainly the following: Oxygen, Carbon, Nitrogen, Magnesium, Neon, Silicon, Iron, Sulfur, Calcium, Argon, Sodium Aluminum... (all elements are present); Medium density: $1410 \mathrm{~kg} / \mathrm{m}^{-3}$; Surface gravity: $274 \mathrm{~m} / \mathrm{s}^{2}$ (28* Earth gravity); Luminosity (total energy radiated light/s): $3.9 \times 1023$ kilowatts; Surface temperature: $5800 \mathrm{~K}$ (effective); Color temperature: $6200 \mathrm{~K}$ (for green emission peak at $470 \mathrm{~nm}$ ); Rotation on itself (sidereal rotation): 25 days at the equator to the poles 37 days; Weight loss: 1 billion kg/s; Average distance (Earth): 149,597,892 km. 


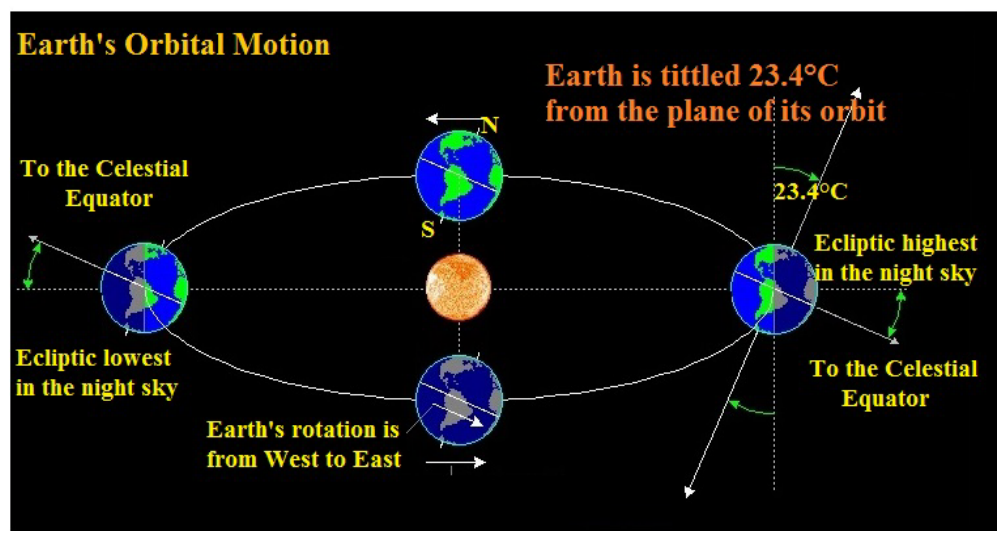

Figure 2. Earth’s orbit and precession angle.

\section{Importance of the Carbon Dioxide $\left(\mathrm{CO}_{2}\right)$ Particularly in Its Relationship to the Clouds}

The weather models used to assess climate change caused by CFCs, have the annoying tendency to neglect the contribution of clouds to the global carbon balance. Yet it has been proven by C. Mbane in 2015 [2]-[4] that clouds are composed of only two elements (dry air and saturated water vapor); and that clouds' saturated water vapor may form precipitations (made of solid or liquid droplets) if and only if they met and dissolve condensation nuclei (mainly the carbon dioxide $\left(\mathrm{CO}_{2}\right)$ in the case of Troposphere). In other words, atmosphere absorbs a significant amount of $\mathrm{CO}_{2}$ in the formation of solid or liquid droplets. The purpose of our work is to make it clear to the international opinion that cloud's saturated water vapor is one of the lung of our planet, far ahead of the green plants respiration or photosynthesis those take place only under the influence of sunlight and in the very lower layers of the troposphere (e.g., well below 25 meters from the surface of the earth). Now each of us could understand and keep in mind the importance of the Carbon dioxide $\left(\mathrm{CO}_{2}\right)$ particularly in its relation to the clouds (e.g., the formation of precipitations). $\mathrm{CO}_{2}$ emissions must therefore not always be presented as a disaster. Because clouds can, without $\mathrm{CO}_{2}$, exist but they will produce less and less precipitations (rain or snow) and oxygen (useful for breathing). The morphology of precipitations (if we refer to the results of Clapeyron (1732) shown in Figure 3) provided by clouds which react with $\mathrm{CO}_{2}$, essentially depends on temperature and humidity of the environment where cloud is formed. These two fundamental thermodynamic parameters (temperature and humidity in that case) distinguish 03 major families of precipitations' birthplace (precipitations' birthplace must be the new name of clouds) as described in Figure 4. Namely:

- Liquid precipitations' birthplaces (located under the $0.0098^{\circ} \mathrm{C}$ isotherm-surface),

- Liquid-solid precipitations’ birthplaces (located just above the $0.0098^{\circ} \mathrm{C}$ isotherm-surface),

- Solid precipitations’ birthplaces (located above the Liquid-solid precipitations’ birthplaces).

\section{Importance of the Localization of $\left(\mathrm{CO}_{2}\right)$ Sources Particularly in Their Relationship to the Precipitations Morphology (Liquid or Solid)}

The Carbon Dioxide $\left(\mathrm{CO}_{2}\right)$ sources are all located either in the depths of the earth and streams, or only at the ground's surface. Figure 4 clearly indicates that, according to the troposphere based conditions of temperature or humidity over a region, some precipitations' birthplace may exist above this region or simply disappear. In other words:

- If the surface temperatures of a region are well above $0.0098^{\circ} \mathrm{C}$, liquid precipitations’ birthplaces (closer to the surface of the ground and therefore to the $\mathrm{CO}_{2}$ sources) will deliver rains to this region (liquid precipitations are call rains from the beginning to the end our paper).

This is what we commonly observe in tropical latitudes. On December 25, 2015; the snow so hoped by many Europeans, did not at all fall in Paris (and in other big cities like Berlin and New York). This Christmas' unusual situation has soaked in total disarray, many people who unfortunately believe that the snows' arrivals are linked to calendar seasons. 


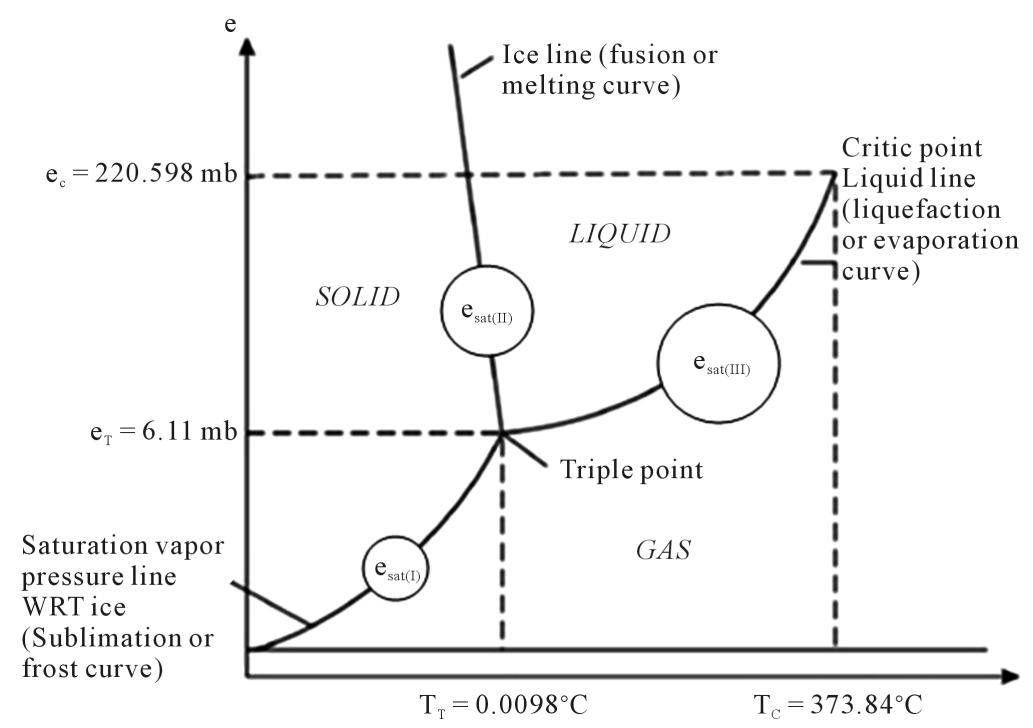

Figure 3. Clausius-Clapeyron (1732) water substances’ saturated curves.

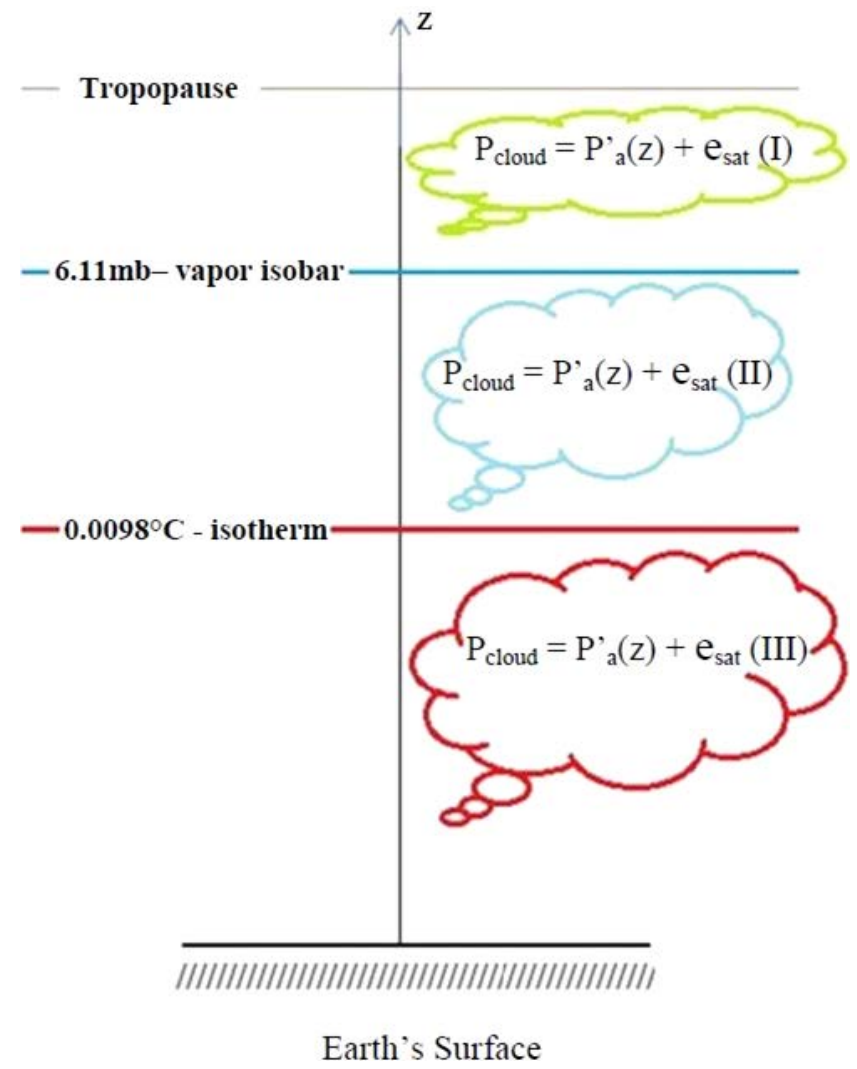

Figure 4. Localizations of major families of clouds (C. Mbane Biouele, 2015).

- If (unlike the situation of tropical latitudes) the surface temperatures of a region are less than $0.0098^{\circ} \mathrm{C}$, liquid precipitations' birthplaces will disappear and been replaced (near the surface of the ground) by solid-liquid precipitations' birthplaces. For that reasons, Troposphere deliver snow as precipitations to regions where surface temperatures are less than $0.0098^{\circ} \mathrm{C}$. The morphology (solid-liquid or solid) of snow will depend on the major families of clouds (Figure 4) which give birth to it.

\section{Mnemonic summary:}




$$
2 \mathrm{SO}_{2}+\mathrm{O}_{2}+2 \mathrm{H}_{2} \mathrm{O} \longrightarrow 2 \mathrm{H}_{2} \mathrm{SO}_{4}
$$

Figure 5. Sulfuric acid chemical reaction.

The Sun, relative to men, is and remains the first earth's climate metronome. Men certainly affect climate, but-whatever the angle at which climate change is analyzed-human action is comparable to a very low amplitude disturbance compared to what the sun makes every day. The question that the continuing warming we observe all this time asks is: which of the two known geometric parameters (earth-sun distance or earth's precession angle in this case) may have changed so that global warming has turned into a nightmare to earthlings? Instead of braving the difficulties from an angle that completely escapes us (such as trying to control the atmosphere global warming), we must make a commitment to move away from our habits, abject forms of pollution that have been listed above (e.g., condemn with the utmost firmness, those who dump tons of fuel in oceans).

\section{Importance of the Sulfur Dioxide ( $\left.\mathrm{SO}_{2}\right)$ Particularly in Its Relationship to Acid Rains}

The sulfuric acid is derived from the chemical reaction below (Figure 5). As everyone can see, earth's atmosphere has all the ingredients to produce precipitation composed only of sulfuric acid. Namely: sulfur dioxide $\left(\mathrm{SO}_{2}\right)$ that can produce erupting volcanoes and other fossil fuels, oxygen $\left(\mathrm{O}_{2}\right)$ which can come from clouds and green plants and water $\left(\mathrm{H}_{2} \mathrm{O}\right)$ that can come from multiple moisture sources. However, no scientific report (to our knowledge) has mentioned the existence of earth's atmosphere precipitation made of sulfuric acid only. This suggests the idea that the above chemical reaction leading to the production of sulfuric acid takes place in Troposphere only in the presence of liquid (or solid) droplets.

In other words, Condensation (which means formation of water droplets) within the composite chemical milieu formed by: carbon dioxide $\left(\mathrm{CO}_{2}\right)$; sulfur dioxide $\left(\mathrm{SO}_{2}\right)$; water $\left(\mathrm{H}_{2} \mathrm{O}\right)$ and oxygen $\left(\mathrm{O}_{2}\right)$, necessarily precedes the formation of sulfuric acid and all this gives leads to the formation of acid rain.

We have now the proof that natural mechanisms to do the cleaning when the atmosphere is polluted with sulfur (or carbon) dioxide exist and this should be highlighted. Therefore, the most dangerous polluters are not necessarily those we condemn today.

\section{Conclusion}

We emphasize that this work is proposed to remind everyone that it is time to better identify the real causes of climate changes. Working for better understanding of earth's atmosphere, Physics is part of this challenge that we will lead somehow to a full success. Natural mechanisms to do the cleaning when the atmosphere is polluted with carbon (or sulfur) dioxide exist and this should be highlighted. According to our pertinent results, the most dangerous polluters of atmosphere are not necessarily those we condemn today. Our planet is threatened by other odious forms of pollution (the little care given to African's urban humid areas is one example) that must be denounced. Telling Africans (as was done at COP21) that they are the ones who pollute less is a heresy with respect to the urban characteristic disorder observed in this continent. Moreover, asking poor countries to turn away from fossil fuels which have nevertheless contributed to the success of the industrialization of the rich countries is a contemptible lie. From a financial point of view, renewable energies (e.g., solar energy) are available only to rich countries. So advising these energies in poor countries is an indecent proposal that can only increase their technological dependence. The transfer of high technology is a chimera that is mirrored to poor countries for decades.

\section{References}

[1] Mbane Biouele, C. (2015) Earth’s Atmosphere Dynamic Balance Meteorology. Scientific Research Publishing Inc., USA, 110 p.

[2] Mbane Biouele, C. (2015) Fundamentals on Thermodynamic Processes behind Cloud's and Rainfall's Formation. Atmospheric and Climate Sciences, 5, 257-265. http://dx.doi.org/10.4236/acs.2015.53019

[3] Mbane Biouele, C. (2015) Relationship between Disruptions of Carbon’s Cyclic Set Natural Transfers and the Upsurge of Weather Conditions with Strong Winds and Heavy Rains. Atmospheric and Climate Sciences, 5, 380-385. 
http://dx.doi.org/10.4236/acs.2015.54029

[4] Mbane Biouele, C. (2015) Useful and Unique Descriptions of Tropospheric Process Which Produce Oxygen and Thereafter Give Birth to Equatorial Electro-Jets. International Journal of Geosciences, 6, 1248-1253. 